\title{
ORBITAL EMPHYSEMA
}

Captain A. G. MURPHY, M.B., Ch.B., M.R.C.S., L.R.C.P., R.A.M.C.

Cambridge Military Hospital, Aldershot

SUMMARY: Three cases of orbital emphysema are described. These resulted from minor trauma which was followed by nose blowing and produced sudden, dramatic and quite alarming symptoms to the patient.

All resolved on conservative treatment of bed rest, broad spectrum antibiotics and avoidance of nose blowing. There were no sequelae.

\section{Introduction}

Orbital emphysema is an accumulation of air in the tissues of the lids or orbit and indicates a communication between the nasal sinuses and the orbit. This can only occur as a result of fracture of bone with laceration of the mucosa; the entrance of air does not occur spontaneously with the fracture but intermittently when the pressure in the upper respiratory passages is later increased, typically on nose blowing.

The condition is not rare but less than 100 cases are reported in the literature (Duke-Elder, 1954).

The injury causing emphysema is frequently slight. Usually it results from a direct injury, such as a blow from a fist (Baudry, 1882, Reber, 1899), not uncommonly as a boxing injury (Linhart, 1943). A few cases have occurred spontaneously in individuals without external injury but following violent sneezing, which has been sufficient to fracture the unusually thin walls of the sinus (Cawthorne, 1938) and occasionally of such severity to cause dislocation of the globe (Desmarres, 1845, Depoutot, 1885, Schanz, 1899, Cotlier, 1940).

\section{Case 1.}

\section{Case Histories}

A 22-year-old officer, while playing rugby football, had a finger ' poked' into the inner canthus region of the right eye producing slight periorbital bruising and minimal discomfort.

Four hours later, after blowing his nose, he felt the right eye suddenly to 'give way' and the eye appeared to protrude and pulsate generally, ' as though on a stalk'. He also noted a tight feeling around the globe and the lids and complained of blurring of vision and diplopia (Fig. 1).

On examination there were marked proptosis with displacement of the globe inferiorly, subcutaneous emphysema of the lids and conjunctiva and crepitus on palpation of the globe and lids (Fig. 2).

Ocular movements were limited in all directions and visual acuity was blurred -count fingers at 1 metre. The fundus and media were clear.

$\mathrm{X}$-ray confirmed the presence of air in the upper (R) orbit with no visible fracture.

The patient was treated with bed rest. Achromycin (Tetracycline) at $250 \mathrm{mg}$ q.d.s. was given and the patient was requested to avoid nose blowing. The condition resolved rapidly and he was discharged on the 5 th day. 


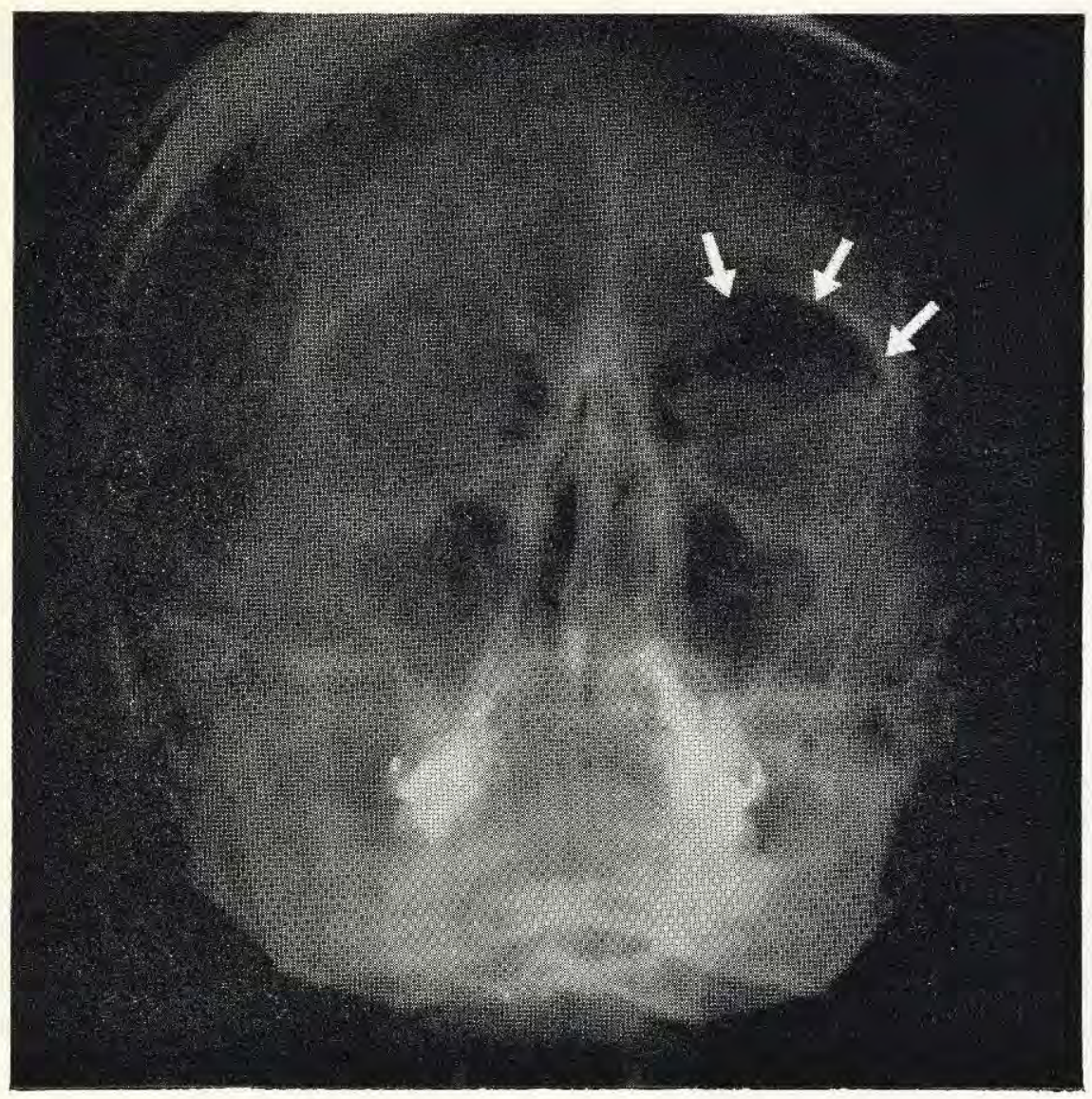

Plate 1. Demonstrating air in orbit as marked. No visible boney fracture.

On review at three weeks no proptosis or displacement of the globe was evident (Figs. 3 and 4). The visual acuity was VR $=\mathrm{VL}=6 / 6$ with full orbital movement (Hess chart normal) and orthophoria for near and distance vision. There were no visual symptoms. The patient has returned to full duty. There have been no reported sequelae.

\section{Case 2.}

A 15-year-old Junior Guardsman was accidentally hit in the region of the left eye by an elbow, with no apparent injury.

One hour later, after blowing his nose, he developed a sudden left periorbital swelling, with inability to open his eyelid.

On examination the left eyelids and periorbital region were swollen but not tense, with crepitus on palpation. No proptosis or displacement of the globe was evident, the visual acuity being normal, with a full range of orbital movement.

$\mathrm{X}$-ray confirmed the presence of air in the orbit with no apparent fracture (Plate 1). The patient was treated conservatively as an out-patient, and there was rapid resolution of the condition over forty-eight hours. 


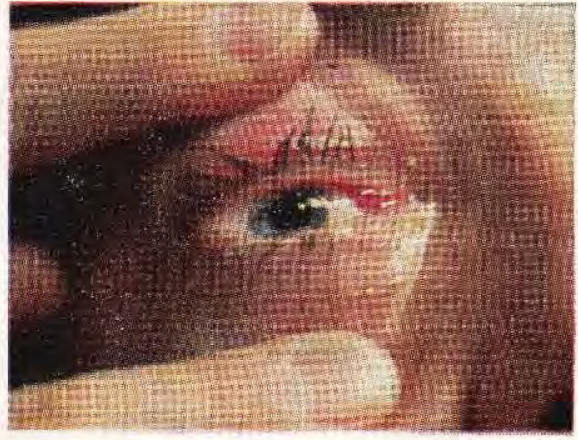

Fig. 1. Case 1 illustrating gross periorbital and subconjunctival emphysema. Site of initial injury at medial canthus visible.

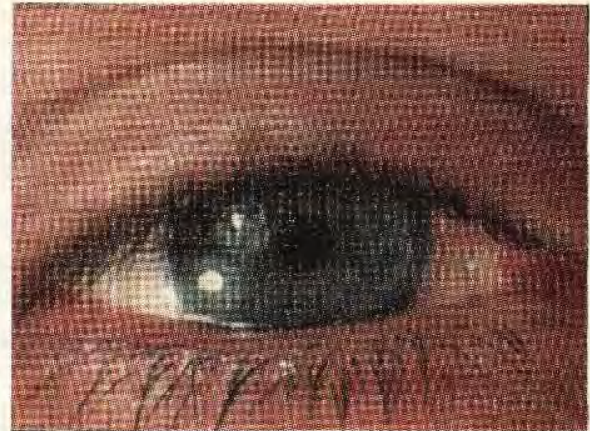

Fig. 3. Case 1 three weeks later showing complete resolution.

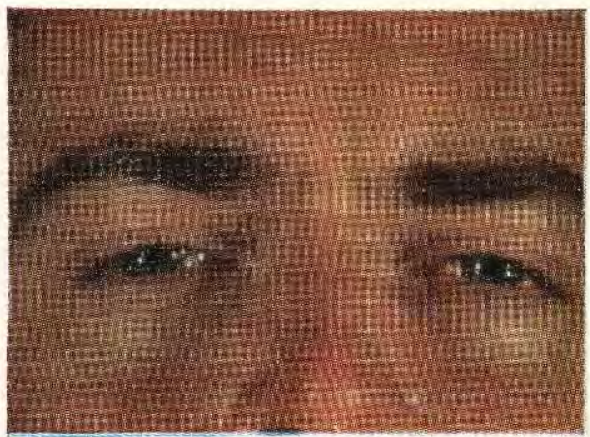

Fig. 4. Case I after three weeks showing absence of proptosis and symmetrical position of eyes.
Fig. 2. Case 1 illustrates proptosis and displacement of globe inferiorly. The eye is forcably held open. 


\section{Case 3.}

A 22-year-old officer, during a boxing match sustained a blow to the left eye, which was considered of no consequence at the time.

Two hours later, after sneezing, the area around the left eye 'came up like a balloon ' producing distressing symptoms of a ' tight' feeling around the eye and inability to open the lids (Figs. 5 and 6 ).

On examination there was a soft fluctuant emphysema of the eyelids with crepitus on palpation. There were no visual symptoms, proptosis or displacement of the globe, and the ocular movements were full.

The patient was treated conservatively with gradual resolution over the following days. There were no sequalae on review at one month.

\section{Discussion}

While orbital emphysema is not rare, it is not often seen and, although it is easily diagnosed, its sudden occurrence is alarming and may cause anxiety to both the patient and the physician.

Essential features in the diagnosis are the history of trauma and the presence of proptosis, which can be reduced by digital pressure and increased by forced expiration. The crepitant feeling in the tissues or lids and orbit or on pressing the globe, is pathognomonic. Confirmation of the diagnosis is by the radiographic demonstration of air in the orbit, together with proof of fracture of bone and with rupture of the mucosa usually on the medial side (Murray, 1949, King and Walsh, 1949). The condition may simulate cellulitis when proptosis is combined with the local effects of contusion and the orbit has been opened only to allow the escape of air (O'Malley, 1943).

Conservative treatment only is required, the air being rapidly absorbed, and the swelling disappeares usually in a few days; only rarely does it persist for periods up to one month. (Baudry, 1882, Humphrey, 1884).

The condition is in itself harmless as the intra-orbital pressure is limited by the pressure generated in the respiratory passages. (Heerfordt (1904) found the highest recorded orbital air pressure to be $80 \mathrm{mg} \mathrm{Hg}$. Pressures above this in experimental conditions have caused tearing of ophthalmic veins with fatal effects (Marcus, 1886).

Complications of orbital emphysema are uncommon and with the advent of broadspectrum antibiotics the incidence of orbital cellulitis, in particular, has been greatly reduced.

In rare cases the air may penetrate to the base of the skull and from there to the subarachnoid space giving rise to a certain degree of compression of the brain parenchyma by air bubbles (Vondra, 1965); this air is visible radiologically as pneumocephalus.

Orbital emphysema is an uncommon clinical feature of a 'blow-out' fracture; the importance of early diagnosis and treatment of this condition is now recognised. This type of fracture may result from a similar injury to the cases discussed. A blunt object such as a ball or fist is forced against the orbital rim (Morton, 1967) producing a bony fracture, usually sited in the posterior nasal part of the orbital floor. This results in downward displacement of the orbital floor with herniation of its contents into the maxillary sinus and is unassociated with damage to the margins of the orbit or the facial bones (Milauskas, 1969). In a recently published series of 23 blow-out fractures no instance of orbital emphysema was recorded (Milauskas, 1969). 


\section{Acknowledgements}

I am grateful to Lieutenant-Colonel K. P. Milne, R.A.M.C., Consultant Ophthalmologist, Cambridge Military Hospital, Aldershot for allowing these cases to be presented. Also Staff-Sergeant P. Poole, B.E.M., R.A.D.C. Photographic Department, R.A.D.C. Training Centre, Aldershot for taking the photographs and to Lederle Laboratories who kindly financed the colour reproduction.

\section{REFERENCES}

Baudry. S. (1882). Note Sur un cad d'emphysema de l'orbite et des paupieres. Lille.

CAWTHORNE, T. (1938). Trans. ophthal. Soc. U.K. 58, 19.

Cotlter, A. (1940). An. argent. Oftal. i, 5.

DePOUTOT. (1885). J. Med. Chir. prat. 56, 114.

Desmarres. (1845). Ann. Oculist, (Paris) 14, 97.

DUKE-ELDER, S. (1954). Textbook of Ophthamology. Vol. 6. Injuries. Kimpton, London.

HEERFORDT, C. F. (1904). Albrecht v. Graefes Arch. Ophthal. 58, 123.

HuMPhrey, L. (1884). Brit. med. J. ii, 1190.

KING, A. B. and Walsh, F. B. (1949). Amer. J. Ophthal. 32, 191 and 379.

LinHART, W. O. (1943). J. Amer. med. Ass. 123, 89.

MARCUS. (1886). Dtsch. Z. Chir. 23, 169.

Milauskas, A. T. (1969). Diagnosis and Management of Blowout Fractures of the Orbit. C. C. Thomas, Illinois.

Morton, W. R. (1967). In Current Concepts of Ophthalmology. Ed. by B. Becker and R. C. Drews, Kimpton, London.

Murray, R. S. (1949). J. Fac. Radiol. (Lond.) 1, 121.

O'MaLly, C. L. C. (1943). Brit. J. Ophthal. 27, 222.

REBER. (1889), Ophthal. Rec. viii, 545 .

Schanz. (1889). Beit. z. Aug. iv (34), 335.

VONDRA, J. (1965). Fractures of the Base of the Skull. Butterworths, London.

\section{Senior Appointment}

Major-General R. A. Smart, C.B.E., Q.H.S., M.B., M.R.C.P., D.P.H., to be Director of Medical Services, British Army of the Rhine, in September 1970, in succession to Major-General J. A. D. Johnston.

A note on his career was published in the Journal, Volume 114, No. 3, 1968.

\section{Honorary Consultant to the Army at Home}

Mr. R. Myles Gibson, E.R.D., M.D., F.R.C.S., has been appointed Honorary Consultant in Neuro-Surgery to the Army at Home. 